\title{
Morphometric effects of testosterone supplementation on certain extremity bones in young swim-trained rats
}

\author{
Abdullah KILCI ${ }^{1}$, Sefa LOK $^{2}$ \\ ${ }^{1}$ Çukurova University, Department physical education and sports, İstanbul, Turkey \\ ${ }^{2}$ Selcuk Universty, Faculty of Sport Science, Konya, Turkey \\ Address Correspondence to S, Lok, e-mail: sefalok@selcuk.edu.tr
}

\begin{abstract}
There has been a dramatic increase in the use of doping agents today. Used by athletes to increase strength, endurance and speed, AAS lead to various negative effects on the human body despite enhancing performance and strength. The purpose of this study was to investigate the morphometric effects of testosterone supplementation on certain extremity bones in young swim-trained rats. The study was conducted with a total of 24 30-day-old male Wistar rats obtained from Selcuk University Experimental Medicine Research and Application Center. The rats were divided into four equal groups of six: control (C), exercise (E), testosterone (T) and testosterone+exercise (TE) groups. The appropriate weekly dose was adjusted for the rats in the testosterone-treated group according to their body weights. The front and back extremity bones of the materials were dissected and the uncovered humerus and femur bones were dried. The length, corpus thickness, cortex cortical thickness and medulla diameter points of each bone were determined and the morphometric measurements were taken. The results were presented as Mean $\pm \mathrm{SD}$. Data were analyzed through comparison between the groups by using ANOVA and Duncan test. The significance level was set at $\mathrm{P}<0.05$. The femur and humerus lengths of the TE, T, E, and $\mathrm{C}$ groups were compared and the respective lengths were femur; $32.24 \pm 1.04$ for the $C$ group, $32.23 \pm 0.28$ for the E group, $31.12 \pm 0.73$ for the TE group and $30.93 \pm 0.72$ for the $T$ group, humerus; $25.74 \pm 0,77$ for the $C$ group, $25.66 \pm 0.25$ fot the E group, $24.68 \pm 0.53$ for the TE group and $24.58 \pm 0.41$ for the $\mathrm{T}$ group. The femur and humerus bones of the rats in the groups given testosterone supplementation (TE and $\mathrm{T})$ were significantly shorter than those of the rats in the other two groups $(\mathrm{p}<0.05)$. However, there were not any statistical differences among the TE, T, E, and C groups in terms of cortex, corpus and medullary diameter measurements of the femur and humerus bones $(\mathrm{p}>0.05)$. The results of the study showed that testosterone supplementation stopped the growth of femur and humerus by causing premature epiphyseal closure in them. Also, even exercise did not reduce the adverse effects of testosterone supplementation. Although some athletes think that prohibited agents used as AAS affect performance positively, these agents should not be used because of their adverse effects on athletes' health and because they are against sports ethics
\end{abstract}

Key words: Testosterone, Exercise, Femur, Humerus

\section{INTRODUCTION}

Anabolic androgenic steroids (AAS) are the synthetic derivatives of the male sex hormone (24, $10,25,6)$. AAS's are used by bodybuilders to attain lower fat mass (7), weight-lifters to lift the maximum amount of weights, athletes to throw hammer, shot, javelin to longer distances than their competitors, swimmers to endure longer and more competitive contests, American football players to develop their muscle mass and power. In addition, they are also widely used among adolescents and young adults in order to have a better physical appearance $(17,10$, $18,2)$.

It has been put forth that AAS's cause cardiomyopathy $(15,4)$ and sudden heart attacks $(11,20)$ in the cardiovascular system; cerebrovascular diseases in the brain and nervous system $(15,1,8)$; dysfunctions in the immune system of the liver while also increasing the risk of tumors, causing hepatitis and increasing LDL while decreasing (16) HDL in the blood (11).

It is put forth that AAS use causes increase in muscular contraction in children, inflammatory reaction in the joints (23), early closure in the epiphysis of the bones $(11,14)$ while especially causing risks of tendon injuries in athletes involved with weight-lifting in addition to damages in the muscular tissue (28).

The use of substances for doping purposes has increased significantly in our day. Doping has negative effects on human health as well as the ethical values and morals of individuals (22). Recently, athletes tend to think that the negative effects of AAS's can be decreased by exercise thus 
leading to an increase in the usage frequency. The objective of this study was to examine the morphometric effects of testosterone supplement applied on young rats subject to swimming exercise on their various extremity bones.

\section{MATERIAL \& METHOD}

This study was carried out on 30-day old 24 male Wistar rats acquired from the "Selcuk University Experimental Medicine Research and Application Center". The study was approved by the Selcuk University Experimental Medicine Research and Application Center Ethical Board (2015-35). Rats were fed ad libitum. The average temperature of the laboratory at which the study was carried out in was $25^{\circ} \mathrm{C}$, whereas the average moisture ratio was \% $52.00 \mathrm{Rh}$. Rats were classified into 4 groups. First group was "Control group" (C) ( n:6 ), the control group was fed for 4 weeks without any application. Second group was "Exercise Group" (E) (n:6), the Exercise group was subject to $30 \mathrm{~min}$. swimming exercise for 5 days of the week. Third group was "Testosterone Group" (T) (n:6). The group was injected testosterone. Fourth group was "Testosterone + Exercise Group" (TE) (n:6). The group was injected testosterone and subjected to $30 \mathrm{~min}$. swimming exercise for 5 days of the week for four weeks. Injected Testosterone (Sustanon ${ }^{\circledR} 250$ Enj, Organon, Oss, Holland) was diluted in $100 \mathrm{mcl}$ peanut oil (Zade peanut oil, Turkey), a dose was $10 \mathrm{mg} / \mathrm{kg}$. The testosterone administered intraperitoneally for a period of 5 days and the same procedure was continued for 4 weeks with a 2-day interval to the Testosterone and Testosterone+Exercise groups. All rats were euthanized at the end of the 4th week via intraperitoneal injection of pentobarbital (Nembutal sodium, Abfar). The front and back extremity bones of the materials were dissected and the humerus and femur bones were dried.

Anatomic reference length (A), corpus thickness (B1 "craniocaudal" + B2 "mediolateral" / 2), cortexcortical bone thickness (C1 "caudal" + C2 "cranial" + C3 "medial" + C4 "lateral" / 4) and medullar diameter-cavum medullare (D1 "craniocaudal" + D2 "mediolateral" / 2) points were determined for the right humerus and femur bones and required morphometric measurements were carried out for each of these points (Figure 1,2).

SPSS 13.0 (SPSS 13,0 for Windows/ SPSS® Inc, Chicago, USA) package software was used for data analysis. The results were presented as Mean $\pm \mathrm{SD}$.
ANOVA and Duncan tests were applied for the comparison of data between groups. The results were evaluated within a \%95 confidence interval and $\mathrm{p}<0.05$ significance level.
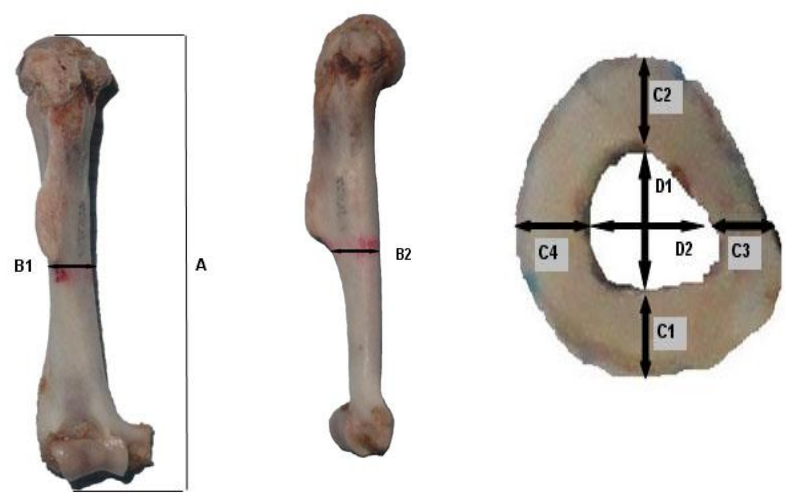

Figüre 1. Reference points (Right crainal and medial face) of humerus length $(\mathrm{A})$, corpus $(\mathrm{B} 1+\mathrm{B} 2 / 2)$, cortex $(\mathrm{C} 1+\mathrm{C} 2+\mathrm{C} 3+\mathrm{C} 4 / 4)$ and medullar calibers $(\mathrm{D} 1+\mathrm{D} 2 / 2)$.

$A=$ Pitch between terminal points of caput humeri and trochlea humeri; $\mathrm{B} 1+\mathrm{B} 2 / 2=$ Corpus thickness of humerus; $\mathrm{C} 1+\mathrm{C} 2+\mathrm{C} 3+\mathrm{C} 4 / 4=$ Cortex thickness (cortical bone- substantiate compacta) of humerus level; D1+D2/2= Caliber of cavum medullar of humerus corpus level.
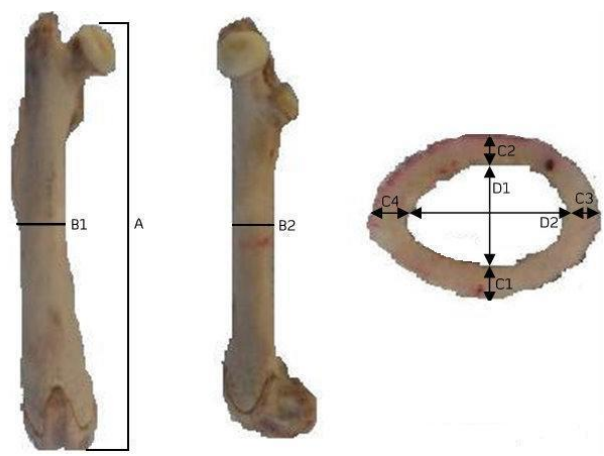

Figüre. 2. Reference points of femur Height (A), Corpus $(\mathrm{B} 1+\mathrm{B} 2 / 2)$, Cortex $(\mathrm{C} 1+\mathrm{C} 2+\mathrm{C} 3+\mathrm{C} 4 / 4)$ and Medullar calibers (D1+D2/2).

A, Pitch between terminal points of rag ossis femoris and trochlea ossis femoris; $\mathrm{B} 1+\mathrm{B} 2 / 2$, corpus thickness of femur; $\mathrm{C} 1+\mathrm{C} 2+\mathrm{C} 3+\mathrm{C} 4 / 4$, Average cortex thickness (cortical bone-substantiate compacta) of femur level; D1+D2/2, caliber of cavum medullar of femur in corpus level. 
Table 1. Comparison of length and thickness of corpus, cortex and medullar diameters of femur bones (Mean \pm SD)

\begin{tabular}{ccccc}
\hline & $\begin{array}{c}\text { TE } \\
(\mathbf{n}: 6)\end{array}$ & $\begin{array}{c}\text { T } \\
(\mathbf{n}: 6)\end{array}$ & $\begin{array}{c}\text { E } \\
(\mathbf{n}: 6)\end{array}$ & $\begin{array}{c}\mathbf{C} \\
(\mathbf{n}: 6)\end{array}$ \\
\hline Length & $31,12 \pm 0,73^{\mathrm{a}}$ & $30,93 \pm 0,72^{\mathrm{a}}$ & $32,23 \pm 0,28^{\mathrm{b}}$ & $32,24 \pm 1,04^{\mathrm{b}}$ \\
\hline Corpus & $3,77 \pm 0,81^{\mathrm{a}}$ & $3,79 \pm 0,12^{\mathrm{a}}$ & $3,71 \pm 0,15^{\mathrm{a}}$ & $3,84 \pm 0,16^{\mathrm{a}}$ \\
\hline Cortex & $0,61 \pm 0,01^{\mathrm{a}}$ & $0,62 \pm 0,02^{\mathrm{a}}$ & $0,61 \pm 0,03^{\mathrm{a}}$ & $0,63 \pm 0,01^{\mathrm{a}}$ \\
\hline $\begin{array}{l}\text { Medull } \\
\text { ar }\end{array}$ & $2,72 \pm 0,02^{\mathrm{a}}$ & $2,73 \pm 0,10^{\mathrm{a}}$ & $2,64 \pm 0,11^{\mathrm{a}}$ & $2,67 \pm 0,07^{\mathrm{a}}$ \\
\hline $\begin{array}{l}\text { a, b= Different letters in the same line are statistically significant (Duncan } \\
\text { test, p<0.05) }\end{array}$
\end{tabular}

When the femur bone lengths of TE, T, E and C were compared, it was observed that the femur length average for the TE group subject to testosterone supplementation was measured as $31,12 \pm 0,73$ and $30,93 \pm 0,72$ for the $T$ group, whereas the femur bone length average for the E group with no testosterone supplementation was measured as $32,23 \pm 0,28$ and that of the $C$ group was measured as $32,24 \pm 1,04$. It was determined that the femur lengths of the rats in $\mathrm{TE}$ and $\mathrm{T}$ groups were shorter than those of the $\mathrm{E}$ and $\mathrm{C}$ groups and that the difference was statistically significant $(p<0,05)$. When the corpus and cortex thicknesses and medullar diameter averages for the femur bones of TE, T, E and $C$ groups were compared, it was concluded that even though there are differences between the averages of groups subject to testosterone supplementation and those that did not receive any testosterone, the difference between all groups was not statistically significant ( $p>0,05)$ (Table 1).

Table 2. Comparison of length and thickness of corpus, cortex and medullar diameters of humerus bones $($ Mean \pm SD)

\begin{tabular}{|c|c|c|c|c|}
\hline & $\begin{array}{c}\text { TE } \\
(\mathrm{n}: 6) \\
\end{array}$ & $\begin{array}{c}\mathrm{T} \\
(\mathrm{n}: 6)\end{array}$ & $\begin{array}{c}E \\
(n: 6) \\
\end{array}$ & $\begin{array}{c}\mathrm{C} \\
(\mathrm{n}: 6)\end{array}$ \\
\hline Length & $24,68 \pm 0,53^{a}$ & $\begin{array}{l}24,58 \pm 0,4 \\
1^{\text {a }}\end{array}$ & $25,66 \pm 0,25^{b}$ & $\begin{array}{l}25,74 \pm 0,77 \\
\text { b }\end{array}$ \\
\hline Corpus & $2,83 \pm 0,11^{a}$ & $\begin{array}{l}2,69 \pm 0,06 \\
\text { a }\end{array}$ & $2,61 \pm 0,11^{a}$ & $2,75 \pm 0,38^{a}$ \\
\hline Cortex & $0,52 \pm 0,01^{a}$ & $\begin{array}{l}0,52 \pm 0,01 \\
\text { a }\end{array}$ & $0,53 \pm 0,01^{\text {a }}$ & $0,54 \pm 0,01^{a}$ \\
\hline Medullar & $1,60 \pm 0,08^{a}$ & $\begin{array}{l}1,58 \pm 0,05 \\
\text { a }\end{array}$ & $1,54 \pm 0,03$ a & $1,54 \pm 0,04^{a}$ \\
\hline
\end{tabular}

When the humerus bone lengths of TE, T, E and $C$ groups were compared, it was observed that the humerus length average of the TE group subject to testosterone supplementation was $24,68 \pm 0,53$ and that of the $\mathrm{T}$ group was measured as $24,58 \pm 0,41$, whereas the humerus length average for the E group with no testosterone supplementation was measured as $25,66 \pm 0,25$ and that of the $C$ group was measured as $25,74 \pm 0,77$. It was determined that the femur lengths of the rats in the TE and $\mathrm{T}$ groups were shorter in comparison with the length averages of the $\mathrm{E}$ and $\mathrm{C}$ groups and that the difference was statistically significant $(p<0,05)$. When the corpus and cortex thicknesses and the medullar diameter averages for the humerus bones of TE, T, E and C groups were compared, it was observed that even though there were differences between the groups with and without testosterone supplementation, this difference was not statistically significant $(p>0,05)$ (Table 2).

\section{DISCUSSION}

The main side effect of anabolic androgenic steroids on the skeletal system is the early closure in the epiphysis of the bones in both adults and adolescents (Maravelias et al. 2005). The side effect of anabolic androgenic steroids on the skeletal system can be the early closure of the growth plate in children as well as shortness in athletes as a result of prolonged androgen use (3).

It was observed in the study that the femur and humerus bone lengths of rats in groups subject to testosterone supplementation were shorter in comparison with the other grops and the difference was statistically significant $(\mathrm{p}<0,05)$.

Li et al. (13) carried out a study to examine the effects of nandrolone application on bone mass and metabolism in rats and they put forth as a result of the study that the humerus bone length of the experiment group subject to AAS was shorter in comparison with the control group.

Bonnet et al. (5) have carried out a study examining the effects of Beta-2 agonists on rat bones in which it was determined that the femur bone length was shorter in the group subject to drug administration whereas the length of the control group was longer.

Prakasam et al. (19) carried out a study examining the effects of testosterone and growth hormone which is an anabolic androgenic steroid on the cortical bone formation and bone development in rats. They determined as a result of their studies that there was a difference between the femur lengths of the rats in the experiment and control group and that the femur length of rats subject to testosterone was shorter in comparison with that of the other group.

Lok (14) carried out a study in which they examined the morphometric effects of testosterone on the femur bone of rats during the puberty period 
in which they put forth that the use of testosterone during the puberty period leads to early epiphyseal closure in the femur bone.

It was determined in the study that testosterone had no effect on the corpus, cortex and medullae of the femur and humerus bones in rats $(p>0,05)$.

Gunness and Orwoll (9) carried out studies in which they put forth that the use of anabolic androgenic steroids cause no statistically significant difference in the femur bone corpus.

Windahl et al. (27) reported that testosterone application has no effects on the cortex thickness of the bone.

Weismann et al. (26) carried out a study in which they examined the effects of testosterone on the bones of male and female rats, as a result of which they put forth that testosterone has no effects on the bone cortex.

Kim et al. (12) put forth in the study in which they examined the effect of the hormonal difference in male and female rats on bone growth that the bone growth has no effect on the cavum medullare diameter in male rats.

Sims et al. (21) carried out a study in which they applied testosterone on female rats as a result of which they put forth that testosterone does not result in any changes in the medullar diameter.

\section{CONCLUSIONS}

When other relevant studies in literature were examined, it can be observed that the banned substances used for doing purposes cause behavioral disorders as well as negative anatomic and morphological changes in organ and tissue structures thereby having adverse effects on the health of athletes and even death in some fields of sports.

It was put forth as a result of the study that testosterone supplementation can cause early epiphyseal closure in femur and humerus bones thus stopping the growth of these bones completely. The use of such substances by athletes and sedentary individuals especially at an early age might have negative effects on bone development.

Hence, even though some athletes think that banned substances which are used as dopings have positive contributions, in reality these substances should not be used due to the negative effects on athlete health.

\section{ACKNOWLEDGEMENTS}

This study is a portion of master thesis and is supported by Selcuk University Scientific Research Projects Coordinator (SUBAPK, 14202027).

\section{REFERENCES}

1. Aggarwal T, Polanco MJ, Scaramuzzino C, Rocchi A, Milioto C, Emionite L, Ognio E, Sambataro F, Galbiati M, Poletti A, Pennuto M. Androgens affect muscle, motor neuron, and survival in a mouse model of SOD1-related amyotrophic lateral sclerosis. Neurobiol Aging, 2014; 35(8) 1929-38.

2. Albertson TE, Chenoweth JA, Colby DK, Sutter ME. The changing drug culture: Use and misuse of appearance-and performance-enhancing drugs. FP Essent, 2016; 441, 30-43.

3. Al-Ismail K, Torreggiani WC, Munk PL, Nicolaou S. Gluteal mass in a bodybuilder: radiological depiction of a complication of anabolic steroid us. Eur Radiol, 2002; 12(6), 1366-9.

4. Baggish AL, Weiner RB, Kanayama G, Hudson JI, Picard MH, Hutter AM, Pope HG. Long-term anabolic-androgenic steroid use is associated with left ventricular dysfunction. Circ Heart Fail, 2010; 3(4), 472-6.

5. Bonnet $\mathrm{N}$, Benhamou $\mathrm{CL}$, Brunet-Imbault $\mathrm{B}$, Arlettaz A, Horcajada MN, Richard O, Vico L, Collomp K, Courteix D. Severe bone alterations under $\beta 2$ agonist teratments: Bone mass, microarchitecture and strength analyses in female rats. Bone, 2005; 37(5), 622-33.

6. De Oliveira DH, Fighera TM, Bianchet LC, Kulak CA, Kulak J. Androgens and bone. Minerva Endocrinol, 2012; 37(4), 30514 .

7. De Siqueira Nogueira FR, De Freitas Brito A, Isidro Vieira T, Coutinho De Oliveira CV, Linka Beniz Gouveia R. Prevalence of anabolic steroids in bodybuilders in the city of Joao PessoaPB: anabolic agents in academies. Gazetta Medica Italiana Archivio per le Scienze Mediche, 2014; 173(5), 299-308.

8. El Osta R, Almont T, Diligent C, Hubert N, Eschwege P, Hubert J. Anabolic steroids abuse and male infertility.Basic Clin Androl, 2016; .26:2

9. Gunness M, Orwoll E. Early induction of alterations in cancellous and cortical bone histology after orchiectomy in mature rats. J Bone Miner Res, 1995; 10(11), 1735-44.

10. Harmer PA. Anabolic-androgenic steroid use among young male and female athletes: is the game to blame. Br J Sports Med, 2010; 44(1), 26-31.

11. Kicman AT. Pharmacology of anabolic steroids. Br J Pharmacol, 2008; 154(3), 502-21.

12. Kim BT, Mosekilde L, Duan Y, Zhang XZ, Tornvig L, Thomsen JS, Seeman E. The structural and hormonal basis of sex differences in peak appendicular bone strength in rats. J Bone Miner Res, 2003; 18(1): 150-5.

13. Li X, Takahashi M, Kushida K, Shimizu S, Hoshino H, Suzuki $\mathrm{M}$, Inoue $\mathrm{T}$. The effect of nandrolone decanoate on bone mass and metabolism overectomized rats with ostepeni. J Bone Miner Metab, 2000; 18(5), 258-63

14. Lok S. Does the use Testosterone Enanthate as a Form of Doping in Sports Cause Early Closure of Epiphyseal in Bones?. Int.J.Morphol, 2015; 33(4), 1201-1204. 
15. Maravelias C, Dona A, Stefanidou M, Spiliopoulou C. Adverse effects of anabolic steroids in athletes: A constant threat. Toxicol Lett, 2005; 158(3), 167-75.

16. Nasseri A, Nadimi A, Nikookheslat SD. Effects of resistance exercise and the use of anabolic androgenic steroids on hemodynamic characteristics and muscle damage markers in bodybuilders, J Sports Med Phys Fitness, 2016; 56(9), 1041-6.

17. Papazisis G, Kouvelas D, Mastrogianni A, Karastergiou A. Anabolic androgenic steroid abuse and mood disorder. A case report Int J Neuropsychopharmacol, 2007; 10(2), 291-3.

18. Piacentino D, Kotzalidis GD, Del Casale A, Aromatario MR, Pomara C, Girardi P, Sani G. Anabolic-androgenic steroid ose and psychopathology in athletes. A systematic review. Curr Neuropharmacol. 2015; 13(1), 101-21.

19. Prakasam G, Yeh JK, Chen MM, Magana MC, Liang CT, Aloia JF. Effects of growth hormone and testosterone on cortical bone formation and bone density in aged orchiectomized rats. Bone, 1999; 24(5), 491-7.

20. Prometti P, Bellini G, Amaddeo P. Premature death in professional wrestlers: cardiovascular and neuropsychiatric effects of anabolic-androgenic steroids. Medicina dello Sport, 2015; 68(2), 231-41.

21. Sims NA, Dupont S, Krust A, Clement-Lacroix P, Minet D, Resche-Rigon M, Gaillard-Kelly M, Baron R. Deletion of estrogen receptors reveals a regulatory role for estrogen receptors in bone remodeling in females but not in males. Bone, 2002; 30(1), 18-25.

22. Tayade MC, Bhamare SM, Kamble P, Jadhav K. Doping in sports: current review. Int J Cur Res Rev, 2013; 5(7), 83-6.

23. Tentori L, Graziani G. Doping with growth hormone/IGF-1, anabolic steroids or erythropoietin: is there a cancer risk? Pharmacol Res, 2007; 55(5), 359-69.

24. Thevis M, Schanzer W. Mass spectrometryin sports drug testing: structure characterization and alalytical assays. Mass Spectrometry Reviews, 2007; 26(1), 79-107.

25. Van Amsterdam J, Opperhuizen A, Hartgens F. Adverse health effects of anabolic-androgenic steroids. Regul Toxicol and Pharmacol, 2010; 57(1), 117-23.

26. Weisman Y, Cassorla F, Malozowski S, Krieg R J, Goldray D, Kaye A M, Somjen D. Sex-specific response of bone cells to gonadal steroids : modulation in perinatally androgenized females and in testicular feminized male rats. Steroids. 1993;58(3): 126-33.

27. Windahl SH, Vidal O, Andersson G, Gustafsson JA, Ohlsson C. Increased cortical bone mineral content but unchanged trabecular bone mineral density in female ER_ mice. J Clin Invest, 1999; 104(7), 895-901.

28. Yavari A. Abuse of anabolic androgenic steroids. Journal of Stress Physiology \& Biochemistry, 2009; 5(3), 22-32. 